\title{
Adsorption of Anionic Surfactants onto Alumina: Characteristics, Mechanisms, and Application for Heavy Metal Removal
}

\author{
Thi Minh Thu Nguyen, ${ }^{1}$ Thi Phuong Thao Do, ${ }^{1}$ Thi Sim Hoang, ${ }^{1}$ Ngoc Viet Nguyen, ${ }^{2}$ \\ Huy Dong Pham, ${ }^{2}$ Trung Dung Nguyen $\mathbb{D}^{3},{ }^{3}$ Thi Ngoc Mai Pham, ${ }^{1}$ Thanh Son Le $\mathbb{D}^{1}{ }^{1}$ \\ and Tien Duc Pham ${ }^{1}{ }^{1}$ \\ ${ }^{1}$ Faculty of Chemistry, VNU University of Science, Vietnam National University, Hanoi, 19 Le Thanh Tong, Hoan Kiem, \\ Hanoi 10000, Vietnam \\ ${ }^{2}$ Center of Environmental Engineering and Chemical Safety, Vietnam Institute of Industrial Chemistry, 2 Pham Ngu Lao, \\ Hoan Kiem, Hanoi 10000, Vietnam \\ ${ }^{3}$ Faculty of Physics and chemical Engineering, Le Quy Don Technical University, 236 Hoang Quoc Viet, Hanoi, Vietnam
}

Correspondence should be addressed to Thanh Son Le; sonlt@vnu.edu.vn and Tien Duc Pham; tienduchphn@gmail.com

Received 26 April 2018; Revised 22 September 2018; Accepted 10 October 2018; Published 13 December 2018

Academic Editor: De-Yi Wang

Copyright ( $\odot 2018$ Thi Minh Thu Nguyen et al. This is an open access article distributed under the Creative Commons Attribution License, which permits unrestricted use, distribution, and reproduction in any medium, provided the original work is properly cited.

\begin{abstract}
We investigated adsorption of anionic surfactants, sodium dodecyl sulfate (SDS) and sodium tetradecyl sulfate (STS), onto alumina $\left(\mathrm{Al}_{2} \mathrm{O}_{3}\right)$ with large size in the present study. The effective conditions for SDS and STS adsorption onto $\mathrm{Al}_{2} \mathrm{O}_{3}$ were systematically studied. The conditions for SDS and STS adsorption onto $\gamma-\mathrm{Al}_{2} \mathrm{O}_{3}$ were optimized and found to be contact time $180 \mathrm{~min}, \mathrm{pH} 4$, and $1 \mathrm{mM} \mathrm{NaCl}$. Adsorption of both SDS and STS onto large $\mathrm{Al}_{2} \mathrm{O}_{3}$ beads increased with an increase of ionic strength, demonstrating that the adsorption is controlled by electrostatic attraction between anionic sulfate groups and positively charged $\mathrm{Al}_{2} \mathrm{O}_{3}$ surface, as well as hydrophobic interactions between long alkyl chains of surfactant molecules. Nevertheless, the hydrophobic interaction in terms of STS adsorption is much higher than that of SDS adsorption. The obtained SDS and STS adsorption isotherms in different $\mathrm{NaCl}$ concentrations onto $\mathrm{Al}_{2} \mathrm{O}_{3}$ beads were fitted well by two-step adsorption. Adsorption mechanisms were disused in detail on the basis of adsorption isotherm, the change in surface charge, and the change in functional surface groups by Fourier-transform infrared spectroscopy (FTIR). The application of surfactant adsorption onto $\mathrm{Al}_{2} \mathrm{O}_{3}$ to remove cadmium ion $\left(\mathrm{Cd}^{2+}\right)$ was also studied. The optimum conditions for $\mathrm{Cd}^{2+}$ removal using surfactant-modified alumina (SMA) are $\mathrm{pH} 6$, contact time $120 \mathrm{~min}$, and ionic strength $0.1 \mathrm{mM} \mathrm{NaCl}$. Under optimum conditions, the removal efficiency of $\mathrm{Cd}^{2+}$ using SMA increased significantly. We demonstrate that SMA is a novel adsorbent for removal of $\mathrm{Cd}^{2+}$ from aqueous solution.
\end{abstract}

\section{Introduction}

Surfactants are widely used chemicals for cleaning. In the application of environmental remediation, the removal of both inorganic and organic contaminants from polluted soils and aquifer sediments is largely enhanced by using surfactants [1]. In this process, surfactant loss reduces the availability of the surfactants for solubilization because of adsorption to soils and sediments [2]. Soils and sediments can be regarded as the mixture of organic and inorganic materials. Metal oxide or mineral oxide is one of major inorganic components of soils and sediments. In order to consider the removal of inorganic and organic substances, therefore, the information on the adsorption behavior of surfactant onto metal oxide will form a basis of the analysis [3-5].

Many experimental studies have been reported on the adsorption of surfactant onto colloidal particles of metal oxides [2, 3, 5-9]. However, the adsorption onto small 
colloidal particles will induce another complicated factor because of aggregation of particles. It is preferable to study an analysis using relatively large beads that can be used to the analysis of transport phenomena and applied for solid-phase extraction technique [10]. In our previously published paper, we successfully analyzed adsorption isotherms of anionic surfactant, sodium dodecyl sulfate (SDS), onto $\alpha-\mathrm{Al}_{2} \mathrm{O}_{3}$ with low specific area at different $\mathrm{NaCl}$ concentrations and $\mathrm{pH}[11]$. The surfactant SDS-modified $\alpha-\mathrm{Al}_{2} \mathrm{O}_{3}$ (SMA) is also studied to remove ammonium ion from aqueous solution [12]. Also, adsorptive removal of both organic and inorganic pollutants using SMA was carefully examined by Adak et al. [13-18], who demonstrate that SMA is a novel adsorbent. Nevertheless, this group did not study on adsorptive removal of very toxic heavy metal cadmium ion $\left(\mathrm{Cd}^{2+}\right)$ using SMA.

It should be noted that alkyl chain of surfactant is an important factor that strongly influences adsorption behavior and structure of adsorbed layer due to the presence of hydrophobic interactions. To predict the effect of alkyl chain, the concept of hemimicelle is well-known. The concept of hemimicelle was initially proposed by Gaudin and Fuerstenau [19]. The two-step adsorption model $[6,20]$ proposed the hemimicelles on a linear-linear scale plot [20]. Based on the theoretical concept of the two-step model, a general adsorption isotherm equation was derived. This equation has been successfully applied to various types of surfactant adsorption isotherms and many systems related to surfactants and polymers [11, 12, 20-24]. Although the effect of alkyl chain to surfactant adsorption onto metal oxides was investigated $[25,26]$, the effective conditions on the adsorption of alkyl sulfate surfactants onto metal oxide have not been studied.

In this paper, we report adsorption of alkyl sulfate surfactants sodium tetradecyl sulfate (STS) and SDS onto the $\mathrm{Al}_{2} \mathrm{O}_{3}$ with a large size. The effective conditions for adsorption such as contact time, $\mathrm{pH}$, and ionic strength have been experimentally studied. The two-step adsorption model is used to fit adsorption isotherms at different ionic strengths. Adsorption mechanisms are suggested based on the adsorption isotherms, surface charge change, and surface modification by Fourier-transform infrared spectroscopy (FTIR). The application of SDS and STS adsorption for cadmium ion removal is also investigated. To the best of our knowledge, this is the first systematic study of SDS and STS adsorption onto $\mathrm{Al}_{2} \mathrm{O}_{3}$ large beads modeling an adsorption isotherm by the two-step model and application for the removal of heavy metal using surfactant-modified alumina (SMA).

\section{Experimental}

2.1. Materials and Chemicals. Ultrapure $\gamma-\mathrm{Al}_{2} \mathrm{O}_{3}$ (Riedelde Haen, Germany), with a diameter of $\sim 50 \mu \mathrm{m}$, was used in the present study. The original $\gamma-\mathrm{Al}_{2} \mathrm{O}_{3}$ beads were treated according to our previously published paper [27]. The treated $\gamma-\mathrm{Al}_{2} \mathrm{O}_{3}$ was used to study adsorption of anionic surfactants.
Anionic surfactants, sodium dodecyl sulfate (SDS) and sodium tetradecyl sulfate (STS) with purity $>95 \%$ which were supplied by Sigma-Aldrich, were used without further purification. Figures 1(a) and 1(b) show the chemical structures of SDS and STS. Cationic dye methylene blue (with purity higher than 98.5\%) and organic solvent chloroform $\mathrm{CHCl}_{3}$ (HPLC grade) from Scharlau, Spain, were used to determine the concentration of SDS and STS by spectrophotometric method. Standard solution of cadmium (1000 ppm in $0.5 \mathrm{M}$ $\mathrm{HNO}_{3}$ ) was purchased from Merck (Germany).

Other chemicals were purchased from Merck or Scharlau of analytical reagent grade. Ultrapure water system (Labconco, USA) with a resistivity of $18.2 \mathrm{M} \Omega \cdot \mathrm{cm}$ was used to produce ultrapure water in preparing all aqueous solutions.

2.2. Adsorption Study. Adsorption isotherms were obtained in a $50 \mathrm{~mL}$ Erlenmeyer flask with stopper at room temperature, controlled by air conditioner $\left(22 \pm 2^{\circ} \mathrm{C}\right)$, using a depletion method. For SDS and STS adsorption studies, a $0.1 \mathrm{~g}$ of treated $\gamma-\mathrm{Al}_{2} \mathrm{O}_{3}$ was mixed with $25 \mathrm{~mL}$ of $\mathrm{NaCl}$ solutions at different concentrations by a shaker. Then, SDS and STS with concentrations from $10^{-5} \mathrm{M}$ to $10^{-2} \mathrm{M}$ were prepared and $\mathrm{pH}$ was adjusted to the original value. After different contact times, $\gamma-\mathrm{Al}_{2} \mathrm{O}_{3}$ was separated from the solutions. The adsorption capacity of SDS onto $\gamma-\mathrm{Al}_{2} \mathrm{O}_{3}$ was determined by the difference in the concentration of SDS and STS solutions before and after adsorption by spectrophotometric method using the following equation:

$$
\Gamma=\frac{\left(C_{\mathrm{i}}-C_{\mathrm{f}}\right) V M}{m},
$$

where $\Gamma$ is the SDS and STS adsorption capacity $(\mathrm{mg} / \mathrm{g}), C_{\mathrm{i}}$ the initial SDS and STS concentration $(\mathrm{mmol} / \mathrm{L}), C_{\mathrm{f}}$ the final SDS and STS concentration ( $\mathrm{mmol} / \mathrm{L}), V$ the volume of sample (L), $M$ the molecular weight of SDS or STS, and $m$ the adsorbent mass of $\mathrm{Al}_{2} \mathrm{O}_{3}(\mathrm{~g})$. The adsorption studies were carried out in triplicates.

The adsorption efficiency $(A, \%)$ of SDS and STS was calculated by

$$
\text { Adsorption efficiency }(A, \%)=\frac{C_{\mathrm{i}}-C_{\mathrm{f}}}{C_{\mathrm{i}}} \times 100 \%,
$$

where $A$ is the adsorption efficiency (\%) and $C_{\mathrm{i}}$ and $C_{\mathrm{f}}$ are the initial SDS and STS concentrations and the final SDS and STS concentrations $(\mathrm{mmol} / \mathrm{L})$, respectively.

For adsorptive removal of heavy metal ion, $A 0.1 \mathrm{~g}$ of adsorbent solution was thoroughly mixed with $25 \mathrm{~mL}$ aqueous solution of $\mathrm{Cd}^{2+}$ of $10 \mathrm{ppm}$ in $50 \mathrm{~mL}$ Erlenmeyer flasks at $22 \pm 2^{\circ} \mathrm{C}$ controlled by an air conditioner. The effects of $\mathrm{pH}$, adsorbent dosage, contact time, and ionic strength on the removal of $\mathrm{Cd}^{2+}$ were investigated. All concentrations of $\mathrm{Cd}^{2+}$ were quantified by flame atomic absorption spectrometry (F-AAS). The removal $(R, \%)$ of $\mathrm{Cd}^{2+}$ was calculated by

$$
\operatorname{Removal}\left(R_{\mathrm{Cd}}, \%\right)=\frac{C_{\mathrm{i}, \mathrm{Cd}}-C_{\mathrm{f}, \mathrm{Cd}}}{C_{\mathrm{i}}, \mathrm{Cd}} \times 100 \%,
$$




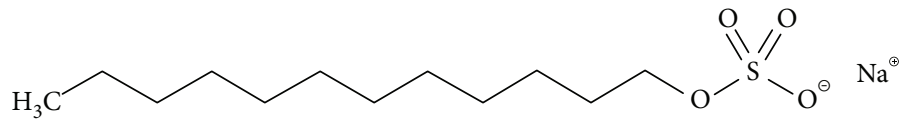

(a)

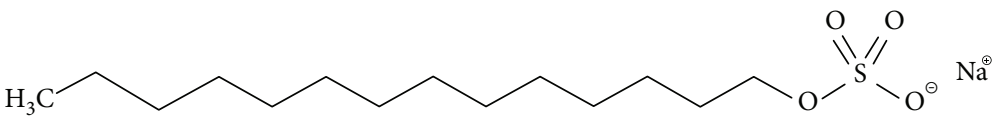

(b)

FIGURE 1: Chemical structures of sodium dodecyl sulfate (SDS) (a) and sodium tetradecyl sulfate (STS) (b).

where $C_{\mathrm{i}, \mathrm{Cd}}$ and $C_{\mathrm{f}, \mathrm{Cd}}$ are initial concentration and final concentration of $\mathrm{Cd}^{2+}$ (ppm), respectively.

2.3. Instrumental Methods. The concentrations of both SDS and STS were determined by extractive spectrophotometric method based on the formation of ion-pair complexes between anionic surfactants and cationic dye, methylene blue in chloroform solvent. Measurements of samples and standard solutions or blanks were carried out simultaneously according to the previously published paper [11]. The absorbances of ion-pair complexes in chloroform phase were measured at a wavelength of $655 \mathrm{~nm}$ by an UV-Vis spectrophotometer (UV-1650PC, Shimadzu) with closed quartz cuvette with $1 \mathrm{~cm}$ optical path length. The relationships between the UV-Vis absorbance and concentrations of SDS and STS of standard calibration curves in different electrolyte concentrations and $\mathrm{pH}$ have a correlation coefficient of at least 0.999 .

All concentrations of $\mathrm{Cd}^{2+}$ in the solution were determined by using an atomic absorption spectrometer (AA6800, Shimadzu, Japan). A hollow cathode lamp (HCL) was used to emit a narrow wavelength of $228.8 \mathrm{~nm}$. The slit width was kept as constant of $0.5 \mathrm{~nm}$ for all F-AAS measurements. A standard curve of $\mathrm{Cd}^{2+}$ by AAS with a correlation coefficient of at least 0.9995 was checked every time before determining unknown samples.

Potentiometric method using a HI 2215 Hanna Instruments $\mathrm{pH}$ meter with a glass combination electrode was used to monitor all $\mathrm{pH}$ of solutions. Three standard buffers (4.0, 7.0, and 10.0, Hanna) were used to calibrate the electrode before measuring $\mathrm{pH}$ of solutions. The change in surface charge of $\gamma-\mathrm{Al}_{2} \mathrm{O}_{3}$ beads were evaluated by monitoring $\mathrm{pH}$ before and after SDS and STS adsorption. A $1 \mathrm{mM} \mathrm{NaCl}$ solution was conducted with the initial $\mathrm{pH}$ in the range of 4-10 using $0.1 \mathrm{M}$ solutions of $\mathrm{NaOH}$ and $\mathrm{HCl}$. Then, the $\mathrm{pH}$ values were measured using the above $\mathrm{pH}$ meter. After equilibrium time of adsorption, the final $\mathrm{pH}$ values were determined. A graph which was plotted between the initial and final $\mathrm{pH}$ against the initial $\mathrm{pH}$ was used to evaluate the change in the surface charge [28].

To confirm surface modification of alumina after SDS and STS adsorption, Fourier-transform infrared spectroscopy (FTIR) was carried out using an Affinity-1S (Shimadzu, Japan). The change of functional groups after $\mathrm{Cd}^{2+}$ adsorption was also evaluated by FTIR. The FTIR spectra were obtained under at the atmospheric pressure, room temperature controlled by an air conditioner $\left(22 \pm 2^{\circ} \mathrm{C}\right)$, and a resolution of $4 \mathrm{~cm}^{-1}$.

\section{Modeling by General Isotherm Equation}

The obtained isotherms of SDS and STS were fitted by a general isotherm equation. The general isotherm equation is as follows [20]:

$$
\Gamma=\frac{\Gamma_{\infty} k_{1} C\left((1 / n)+k_{2} C^{n-1}\right)}{1+k_{1} C\left(1+k_{2} C^{n-1}\right)},
$$

where $\Gamma$ is the amount of adsorbed SDS and STS $(\mathrm{mg} / \mathrm{g}), \Gamma_{\infty}$ is the maximum adsorption amount $(\mathrm{mg} / \mathrm{g})$, and $n$ is the number of hemimicelle concentration while $k_{1}(\mathrm{~g} / \mathrm{mg})$ and $k_{2}(\mathrm{~g} / \mathrm{mg})^{n-1}$ are equilibrium constants for the first step and second step, respectively. $C$ denotes the equilibrium concentrations of SDS and STS in solution $(\mathrm{mmol} / \mathrm{L})$.

The selected fitting parameters for surfactant adsorption were described in the previously published papers [11].

\subsection{Results and Discussion}

\subsection{Adsorption of SDS and STS onto Alumina}

3.2.1. Effect of Contact Time. Contact time influences the completeness of adsorption equilibration. The effect of contact time on the adsorption efficiency of SDS and STS onto $\mathrm{Al}_{2} \mathrm{O}_{3}$ was shown in Figure 2. Figure 2 indicates that the adsorption efficiencies of SDS and STS increased from 0 to $180 \mathrm{~min}$. After $180 \mathrm{~min}$, adsorption changed insignificantly. It suggests that adsorption reaches the equilibrium at $180 \mathrm{~min}$ for both SDS and STS. Thus, $180 \mathrm{~min}$ is suitable for adsorption of SDS and STS. As can be seen in Figure 2, the adsorption of STS reaches to equilibrium faster than SDS adsorption. The adsorption of SDS and STS in our case is much faster than the adsorption of alkyl sulfate surfactants onto metal oxides $[11,29,30]$. Figure 2 also shows that all error bars showing the replicates are small, indicating that the experiments have very good repeatability.

3.2.2. Effect of $p H$. Solution $\mathrm{pH}$ plays an important role in the adsorption of anionic surfactant onto $\mathrm{Al}_{2} \mathrm{O}_{3}$ because it can influence the surface charge of $\mathrm{Al}_{2} \mathrm{O}_{3}$ while the charging behavior of SDS and STS is independent on $\mathrm{pH}$. The effect of initial $\mathrm{pH}$ on the SDS and STS adsorption onto $\mathrm{Al}_{2} \mathrm{O}_{3}$ 


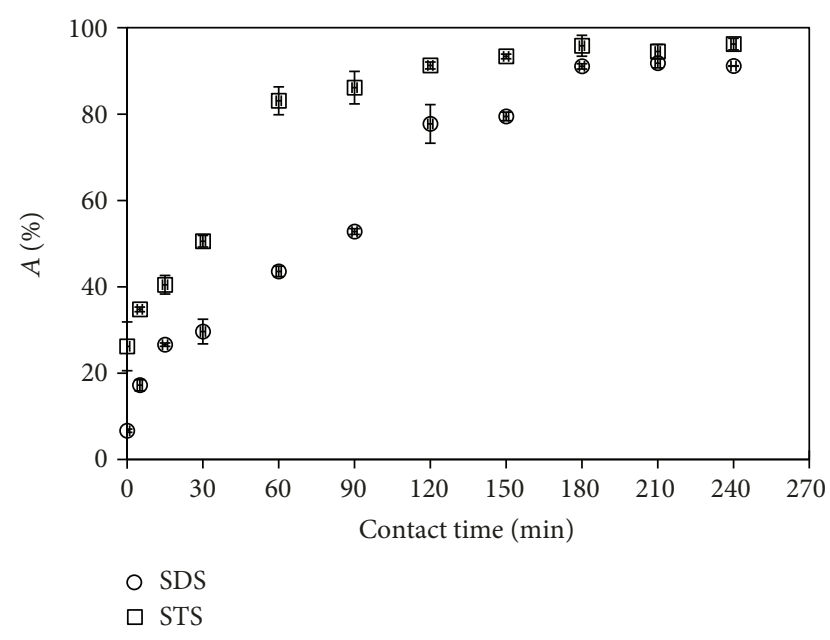

FIGURE 2: Effect of contact time on the adsorption efficiency of SDS and STS onto $\mathrm{Al}_{2} \mathrm{O}_{3}$. Error bars show standard deviations of three replicates.

was investigated in the $\mathrm{pH}$ range of $3-10$ in $1 \mathrm{mM} \mathrm{NaCl}$ (Figure 3).

Figure 3 shows that the adsorption of SDS and STS onto $\mathrm{Al}_{2} \mathrm{O}_{3}$ achieves the maximum at $\mathrm{pH}$. The adsorption decreased with increasing solution $\mathrm{pH}$ from $\mathrm{pH} 4$ to $\mathrm{pH} 7$ for both SDS and STS due to the decrease of positive charge of $\mathrm{Al}_{2} \mathrm{O}_{3}$. These trends are similar to the adsorption of SDS onto $\alpha-\mathrm{Al}_{2} \mathrm{O}_{3}$ with small specific area [11]. The adsorption of SDS onto $\alpha-\mathrm{Al}_{2} \mathrm{O}_{3}$ induced proton concomitant so that the surface charge of $\alpha-\mathrm{Al}_{2} \mathrm{O}_{3}$ grew up with an increase SDS adsorption. The change in surface charge upon SDS and STS adsorption will be discussed in Adsorption Mechanisms.

On the one hand, at $\mathrm{pH}$ higher than 7 , adsorption increased because the charge reversal of $\mathrm{Al}_{2} \mathrm{O}_{3}$ took place and adsorption here was induced by hydrophobic interaction. The dissolution of $\gamma-\mathrm{Al}_{2} \mathrm{O}_{3}$ can take place at $\mathrm{pH} 3$ so that adsorption of both SDS and STS is decreased. At $\mathrm{pH} 3$, the error bars are highest and residual surfactants after adsorption are not stable that is strongly affected by $\gamma-\mathrm{Al}_{2} \mathrm{O}_{3}$ dissolution.

3.2.3. Effect of Ionic Strength. Ionic strength affects electrostatic attraction between anionic surfactants and positively charged $\mathrm{Al}_{2} \mathrm{O}_{3}$ surface. As can be seen in Figure 4, the adsorption efficiencies increase from 0 to $1 \mathrm{mM} \mathrm{NaCl}$ then they decrease from 1 to $200 \mathrm{mM}$. At very low salt concentration, adsorption of both SDS and STS is controlled by both electrostatic and hydrophobic interactions [31, 32]. However, the desorption of surfactant is enhanced with increasing salt concentration [33]. It should be noted that the concentrations of both SDS and STS equal to $10^{-5} \mathrm{M}$, adsorption mainly induced by electrostatic attraction so that adsorption decreases with increasing salt concentration. In order to understand adsorption behavior of sulfate surfactants and effect of alkyl chain, adsorption isotherms were taken and discussed in detail in the next section.

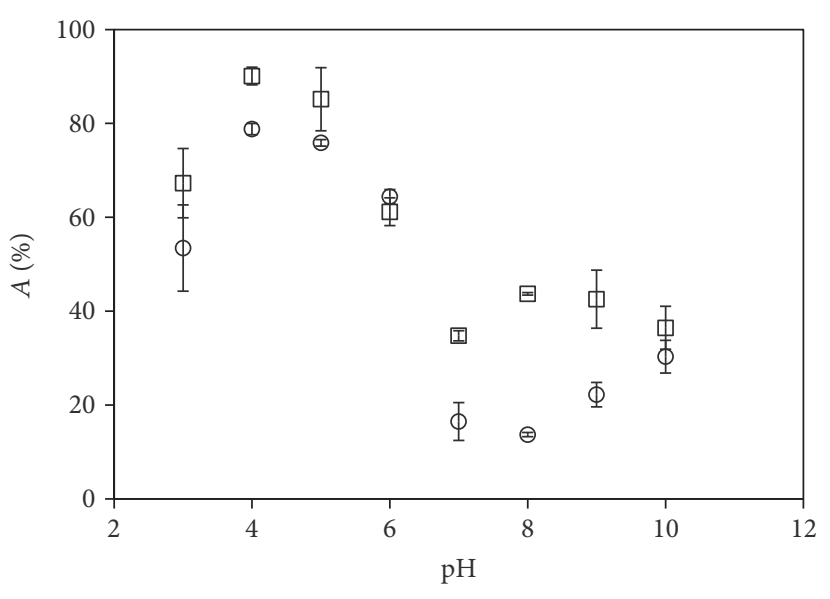

O SDS

$\square$ STS

FIGURE 3: Effect of $\mathrm{pH}$ on the adsorption efficiency of SDS and STS onto $\mathrm{Al}_{2} \mathrm{O}_{3}$. Error bars show standard deviations of three replicates.

3.2.3.1. Adsorption Isotherms of SDS and STS onto $\mathrm{Al}_{2} \mathrm{O}_{3}$. The effect of ionic strength on SDS and STS adsorption onto alumina surface is well demonstrated in the isotherms. The presented isotherms show two steps at different ionic strengths. The calculated curves by the two-step adsorption model shown as the solid lines in Figures 5 and 6 can reasonably represent experimental data by using the fit parameters (Table 1). From the fitting procedure according to our published paper [11], the values of $n$ are chosen about 3 for SDS and 3.2 for STS. Although the values of $n$ obtained from this model are much smaller than the measured aggregation number using spectroscopic methods [5, 34], the results from the two-step model are useful to evaluate the effect of ionic strength.

Figure 5 shows that at different salt concentrations, the adsorption density of SDS decreases with an increase of salt concentration because the electrostatic attraction between the negatively charged SDS head groups and positively charged $\gamma-\mathrm{Al}_{2} \mathrm{O}_{3}$ surface is decreased by increasing salt concentrations. The isotherms of SDS adsorption at lower salt are above others at high salt. For STS adsorption, this trend is appropriated at low STS concentration (Figure 6). However, at high surfactant concentration, the adsorption density of STS increases with increasing salt concentration by screening of repulsive force between negatively charged sulfate ion.

At the high ionic strength (10 and $100 \mathrm{mM} \mathrm{NaCl})$, maximum adsorption of STS is higher than that of SDS (Table 1). Especially, maximum adsorption capacity of STS is 2.4 times greater than that of SDS. It implies that adsorption of alkyl sulfate is strongly controlled by hydrophobic interaction at high ionic strength. The results are in good agreement with previously published papers $[11,32,35]$. The reasons may be due to the significant decrease in critical micelle concentration (CMC) when increasing ionic strength. However, at low ionic strength $(1 \mathrm{mM} \mathrm{NaCl})$, adsorption of SDS is higher than that of STS. It suggests that the electrostatic attraction is stronger for SDS adsorption than for STS adsorption at low 


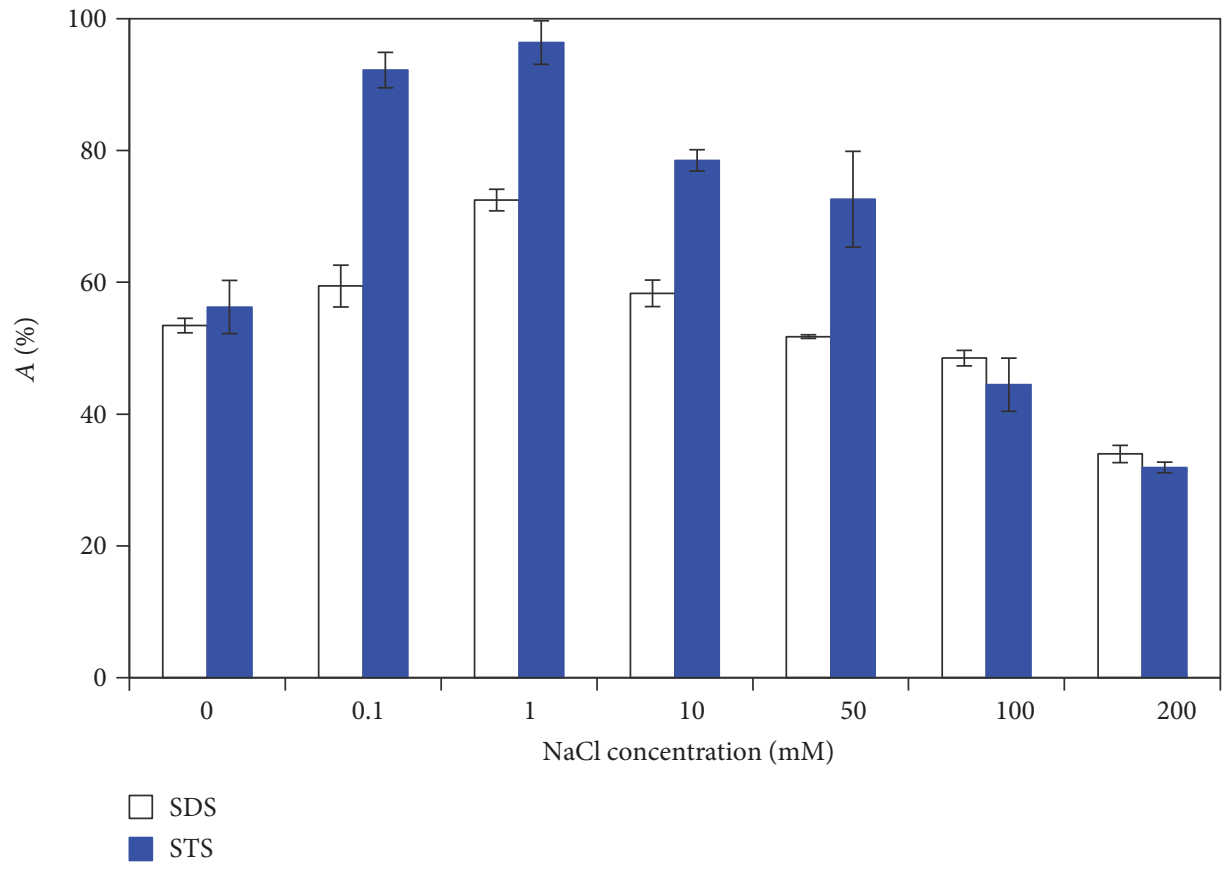

FIGURE 4: Effect of ionic strength on the adsorption efficiency of SDS and STS onto $\mathrm{Al}_{2} \mathrm{O}_{3}$. Error bars show standard deviations of three replicates.

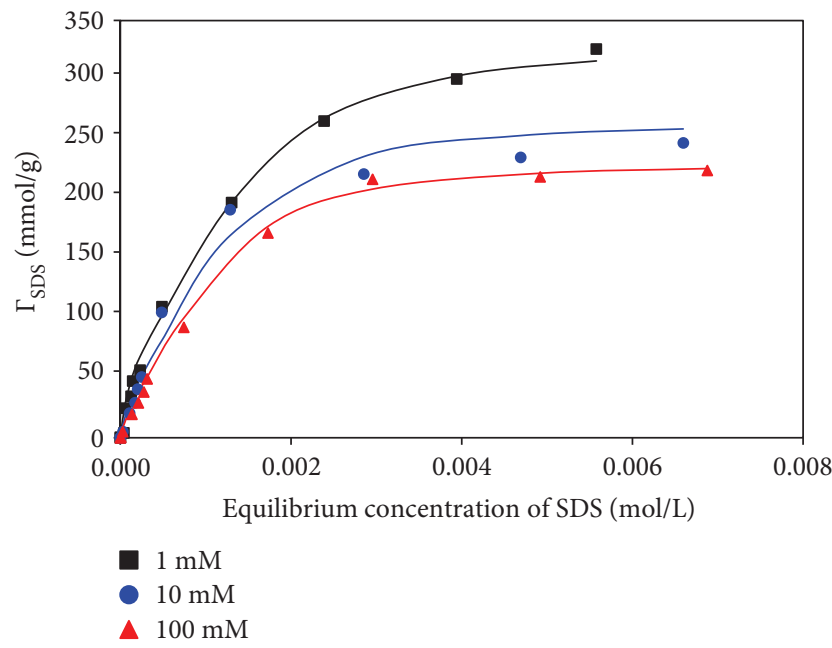

Figure 5: Adsorption isotherms of SDS onto $\gamma$ - $\mathrm{Al}_{2} \mathrm{O}_{3}$ in different $\mathrm{NaCl}$ concentrations $(\mathrm{pH} 4)$. While the points are experimental data, the solid lines are the results of the 2-step adsorption model.

salt. When increasing salt, electrostatic attraction is reduced and hydrophobic interaction is enhanced. Another thing is that carbon chain length plays an important role in the hydrophobic force so that the adsorption increases with increase carbon chain at high ionic strength. Also, the values of $k_{2}$ seem to be a parameter to evaluate the effect of carbon chain in which $k_{2}$ is much higher for STS adsorption than for SDS adsorption. On the one hand, the values of $k_{1}$ changed insignificantly. We indicate that the adsorption of alkyl sulfate surfactants is induced by both electrostatic and hydrophobic interactions.

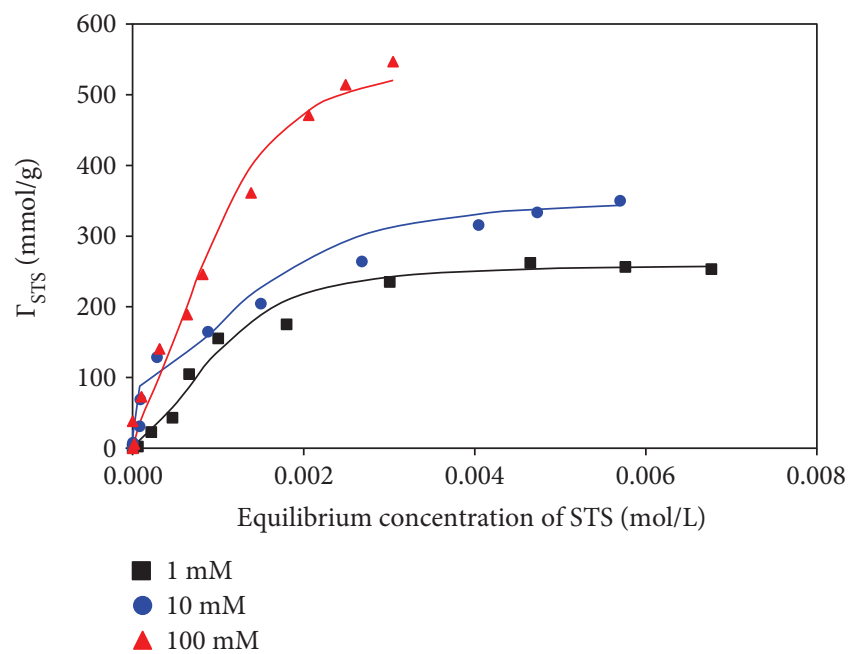

FIgure 6: Adsorption isotherms of STS onto $\mathrm{Al}_{2} \mathrm{O}_{3}$ in different $\mathrm{NaCl}$ concentrations. While the points are experimental data, the solid lines are the results of the 2 -step adsorption model.

3.2.4. Adsorption Mechanisms. Adsorption of alkyl sulfate surfactants onto $\gamma-\mathrm{Al}_{2} \mathrm{O}_{3}$ is discussed in detail based on the change in surface charge, the change in functional groups by FTIR, and the adsorption isotherm.

The change in surface charge was evaluated by the difference of initial $\mathrm{pH}$ and final $\mathrm{pH}$ after SDS and STS adsorption (Figure 7).

The adsorption amounts of SDS and STS are much higher than those of the proton concomitant. Nevertheless, the proton adsorption is significant so that after SDS and STS adsorption, the differences of $\mathrm{pH}(\Delta \mathrm{pH})$ are high, 
TABLE 1: The fit parameters for the SDS and STS adsorption isotherms onto $\gamma-\mathrm{Al}_{2} \mathrm{O}_{3}$ at different $\mathrm{NaCl}$ concentrations ( $\mathrm{pH} 4$ ). The maximum adsorbed amount $\Gamma_{\infty}$, the equilibrium constants $k_{1}$ and $k_{2}$ for the first step and second step, respectively, and $n$ the aggregation number of hemimicelle of SDS and STS molecules.

\begin{tabular}{lccccc}
\hline$C_{\mathrm{NaCl}}(\mathrm{mM})$ & Surfactant & $\Gamma_{\infty}(\mathrm{mg} / \mathrm{g})$ & $k_{1}(\mathrm{~g} / \mathrm{mg})$ & $k_{2}(\mathrm{~g} / \mathrm{mg})^{n-1}$ & $n$ \\
\hline 100 & SDS & 230 & $4 \times 10^{3}$ & $4 \times 10^{5}$ & 3.0 \\
100 & STS & 555 & $3 \times 10^{3}$ & $4 \times 10^{6}$ & 3.2 \\
10 & SDS & 265 & $4.5 \times 10^{3}$ & $7 \times 10^{5}$ & 3.0 \\
10 & STS & 355 & $5 \times 10^{3}$ & $3 \times 10^{6}$ & 3.3 \\
1 & SDS & 330 & $6 \times 10^{3}$ & $5 \times 10^{5}$ & 3.0 \\
1 & STS & 260 & $3 \times 10^{3}$ & $4 \times 10^{6}$ & 3.2 \\
\hline
\end{tabular}

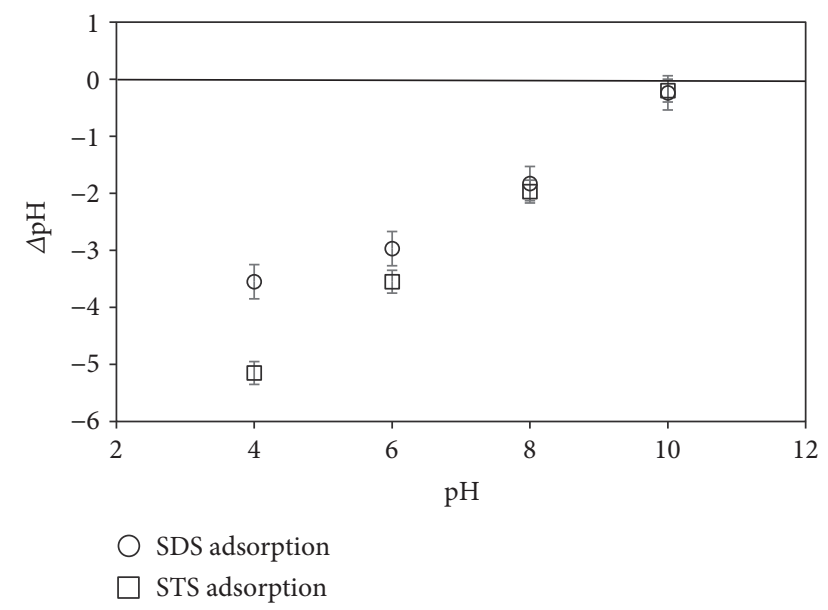

Figure 7: The differences of $\mathrm{pH}(\Delta \mathrm{pH})$ after SDS and STS adsorption as a function of initial $\mathrm{pH}$.

especially for low $\mathrm{pH}$. The screening by SDS and STS molecules plays an important role in inducing the proton adsorption. The effect of alkyl chain length is clearly observed in Figure 7 in which $\Delta \mathrm{pH}$ for STS adsorption is always higher than that for SDS adsorption. These results agreed well with the results of adsorption isotherm of SDS and STS. The influence of $\mathrm{pH}$ in proton concomitant is high when surfactant molecules adsorb with head groups toward the $\gamma-\mathrm{Al}_{2} \mathrm{O}_{3}$ surface. This trend is similar to the case of SDS adsorption onto $\alpha-\mathrm{Al}_{2} \mathrm{O}_{3}$ with small surface area. On the other hand, the hydrophobic core is limited so that net charge at the surface site of the bilayer is very low [35]. These findings suggest that the electrostatic interaction is of great important for adsorption of SDS and STS onto $\gamma-\mathrm{Al}_{2} \mathrm{O}_{3}$.

The surfactant adsorption mechanism is suggested by comparing the FTIR spectrum of unmodified $\gamma-\mathrm{Al}_{2} \mathrm{O}_{3}$ (Figure 8) and the $\gamma-\mathrm{Al}_{2} \mathrm{O}_{3}$ beads after adsorption (Figures 9 and 10). Figure 8 shows that the peaks appearing at $3564.45 \mathrm{~cm}^{-1}$ is assigned for $-\mathrm{OH}$ stretching vibration. The absorption band at $1645.28 \mathrm{~cm}^{-1}$ is due to the water molecule in the sample [36]. The broaden peak between
$893.04 \mathrm{~cm}^{-1}$ and $522.71 \mathrm{~cm}^{-1}$ confirms the bending vibration of $\mathrm{Al}-\mathrm{O}$ in $\gamma-\mathrm{Al}_{2} \mathrm{O}_{3}$. On the other hand, Figure 9 shows that the relative intensity of asymmetrical and symmetrical stretching of $-\mathrm{CH}_{2}$ - present at 2922 and $2856 \mathrm{~cm}^{-1}$ decreases dramatically in the spectra of $\gamma-\mathrm{Al}_{2} \mathrm{O}_{3}$ after SDS adsorption compared to SDS powder. On the other hand, Figure 10 still shows the strong peaks of stretching of $-\mathrm{CH}_{2}-$ present at 2926 and $2860 \mathrm{~cm}^{-1}$ after STS adsorption onto $\gamma-\mathrm{Al}_{2} \mathrm{O}_{3}$. These indicate that hydrophobic interaction takes place on the surface of $\gamma-\mathrm{Al}_{2} \mathrm{O}_{3}$. In addition, the hydrophobic interaction in case of STS adsorption is stronger than that of SDS adsorption. In addition, the peaks of $\mathrm{SO}_{4}^{2-}$ at about $1254 \mathrm{~cm}^{-1}$ and $1218 \mathrm{~cm}^{-1}$ occur very strongly in the spectrum of SDS and STS and while these bands do not appear in the spectra of $\gamma-\mathrm{Al}_{2} \mathrm{O}_{3}$ after SDS and STS adsorption (Figures 9 and 10). This suggests that SDS and STS have sulfate head groups toward the surface of $\gamma-\mathrm{Al}_{2} \mathrm{O}_{3}$ by electrostatic attraction. Admicelles with the bilayer containing both the first layer head-on toward $\gamma-\mathrm{Al}_{2} \mathrm{O}_{3}$ and second layer head-out toward solution were formed [11]. Also, admicelles are enhanced in the case of STS than SDS. The results are also in good agreement with adsorption isotherm shown in the above section. The results of FTIR spectra of $\gamma$ $\mathrm{Al}_{2} \mathrm{O}_{3}$ after SDS and STS adsorption combined with the adsorption isotherm suggest that SDS and STS molecules mainly adsorb on the surface of $\gamma-\mathrm{Al}_{2} \mathrm{O}_{3}$ by both electrostatic attraction as well as probably by hydrophobic interaction. The hydrophobic interaction in the case of STS is much stronger than that of SDS, demonstrating that the effect of hydrocarbon alkyl chain length is of great importance for alkyl sulfate surfactant adsorption.

\subsection{Adsorptive Removal of Cadmium Using Surfactant- Modified Alumina (SMA)}

3.3.1. Influence of $p H$. The $\mathrm{pH}$ of the solution is one of the most important factors that strongly affect the removal of $\mathrm{Cd}^{2+}$. The $\mathrm{pH}$ can affect the charging behavior of adsorbents and the species of $\mathrm{Cd}^{2+}$ in aqueous solution. In order to evaluate the role of surfactant modification, we compare three adsorbents. $\gamma-\mathrm{Al}_{2} \mathrm{O}_{3}$ denotes without surfactant while $\gamma-\mathrm{Al}_{2} \mathrm{O}_{3}$ materials after STS preadsorption and SDS preadsorption are called with STS modification and with SDS modification, respectively. The effect of initial $\mathrm{pH}$ on removal of $\mathrm{Cd}^{2+}$ using three adsorbents in the range of $\mathrm{pH} 3-7$ in $1 \mathrm{mM} \mathrm{NaCl}$ is indicated in Figure 11.

As can be seen in Figure 11, the removal of $\mathrm{Cd}^{2+}$ using three adsorbents (without surfactant, with STS modification, and with SDS modification) increases with increasing $\mathrm{pH}$ from $\mathrm{pH} 3$ to 6 . The removal of $\mathrm{Cd}^{2+}$ with surfactant modification is always higher than in the case without surfactant, demonstrating that surfactant-modified $\gamma-\mathrm{Al}_{2} \mathrm{O}_{3}$ is a better adsorbent compared with $\gamma-\mathrm{Al}_{2} \mathrm{O}_{3}$ without surfactant. At the optimum $\mathrm{pH}$, the removal of $\mathrm{Cd}^{2+}$ increases from $62.7 \%$ (without surfactant) to about $94.6 \%$ (with SDS modification). In addition, the differences between STS modification and SDS modification are insignificant. Since SDS is a more common chemical compared with STS, SDSmodified $\gamma-\mathrm{Al}_{2} \mathrm{O}_{3}$ (SMA) is chosen for further study in the 


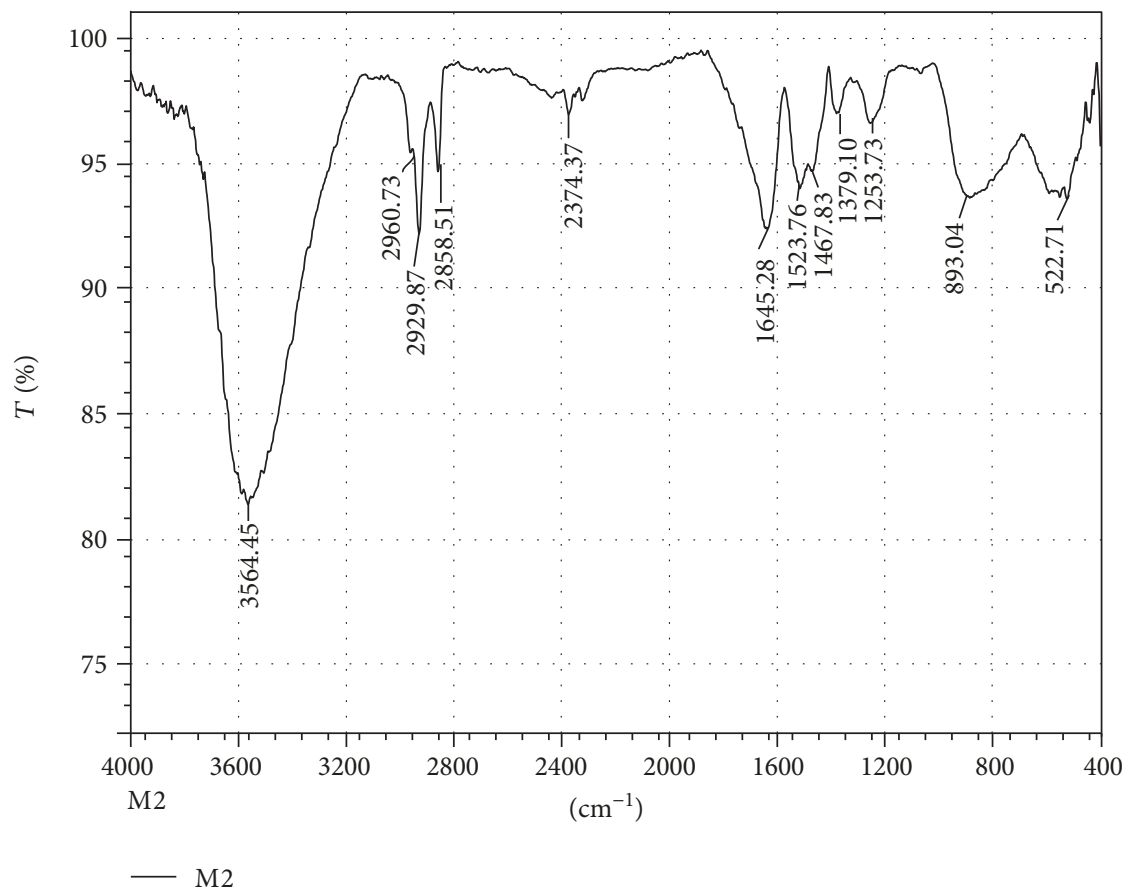

FIGURE 8: The FTIR spectra in the wavenumber range of $400-4000 \mathrm{~cm}^{-1}$ of unmodified $\gamma$ - $\mathrm{Al}_{2} \mathrm{O}_{3}$.

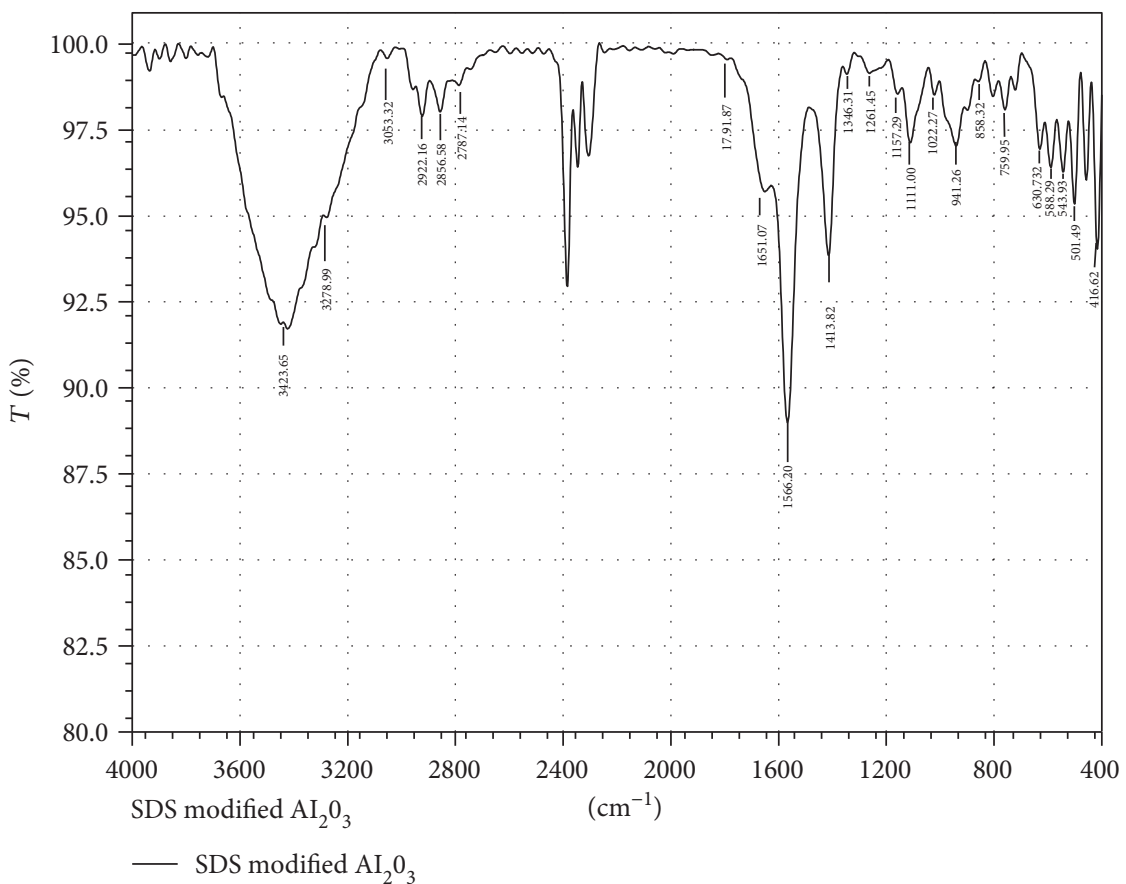

FIGURE 9: FTIR spectrum of $\gamma-\mathrm{Al}_{2} \mathrm{O}_{3}$ after SDS adsorption in the wavenumber range of $400-4000 \mathrm{~cm}^{-1}$.

removal of $\mathrm{Cd}^{2+}$ from aqueous solution. The optimum $\mathrm{pH}$ for the removal of $\mathrm{Cd}^{2+}$ by SMA is $\mathrm{pH} 6$.

3.3.2. Influence of Contact Time. Figure 12 shows that the removal of $\mathrm{Cd}^{2+}$ using SMA is rapidly increased. The removal increases with increasing contact time from $5 \mathrm{~min}$ to $120 \mathrm{~min}$. After $120 \mathrm{~min}$, the removal of $\mathrm{Cd}^{2+}$ changes very little. It indicates that the adsorption of $\mathrm{Cd}^{2+}$ using SMA reaches equilibrium at $120 \mathrm{~min}$. Thus, $120 \mathrm{~min}$ is chosen for removal of $\mathrm{Cd}^{2+}$ using SMA.

3.3.3. Influence of Ionic Strength. Ionic strength affects the electrostatic attraction between $\mathrm{Cd}^{2+}$ onto SMA and the SDS remaining on the $\gamma-\mathrm{Al}_{2} \mathrm{O}_{3}$ surface. Figure 13 shows that the removal efficiency decreases with increasing $\mathrm{NaCl}$ concentration, except for salt free $(0 \mathrm{mM} \mathrm{NaCl})$. Without salt, 


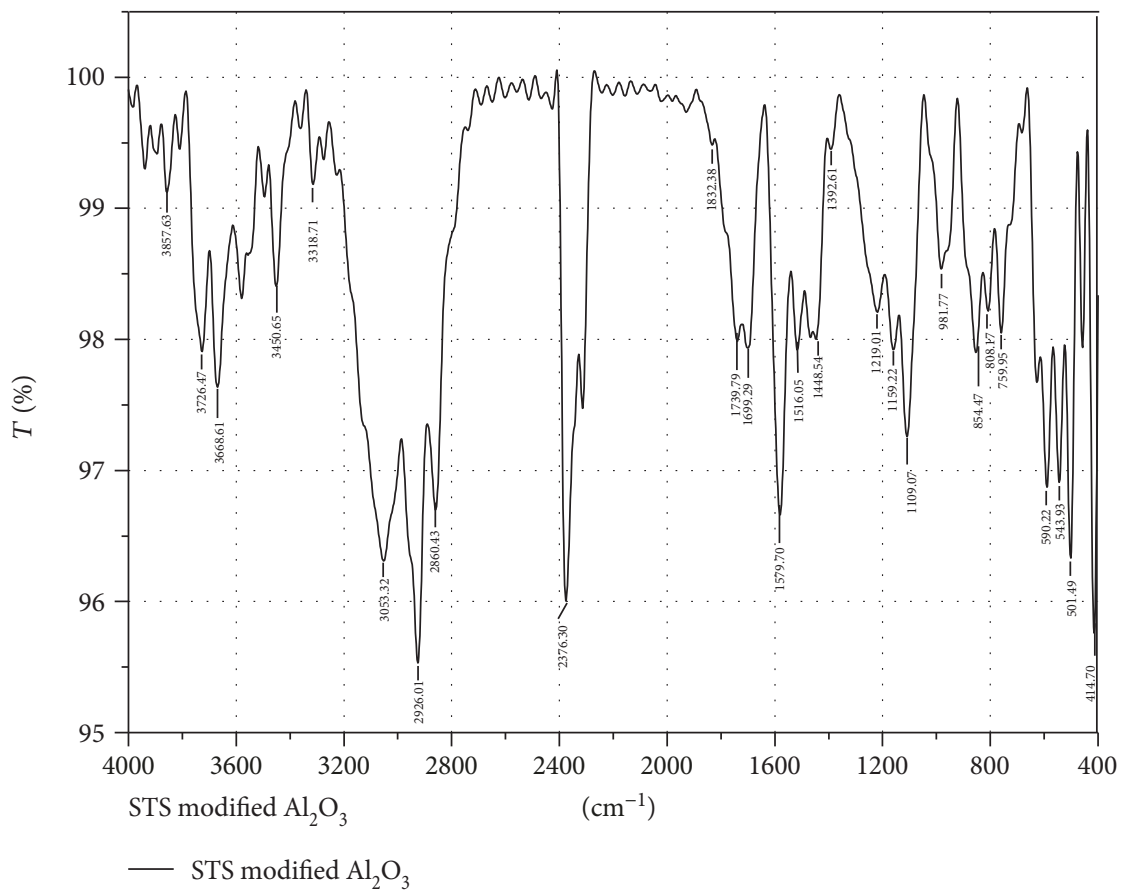

FigURE 10: FTIR spectrum of $\gamma-\mathrm{Al}_{2} \mathrm{O}_{3}$ after STS adsorption in the wavenumber range of $400-4000 \mathrm{~cm}^{-1}$.

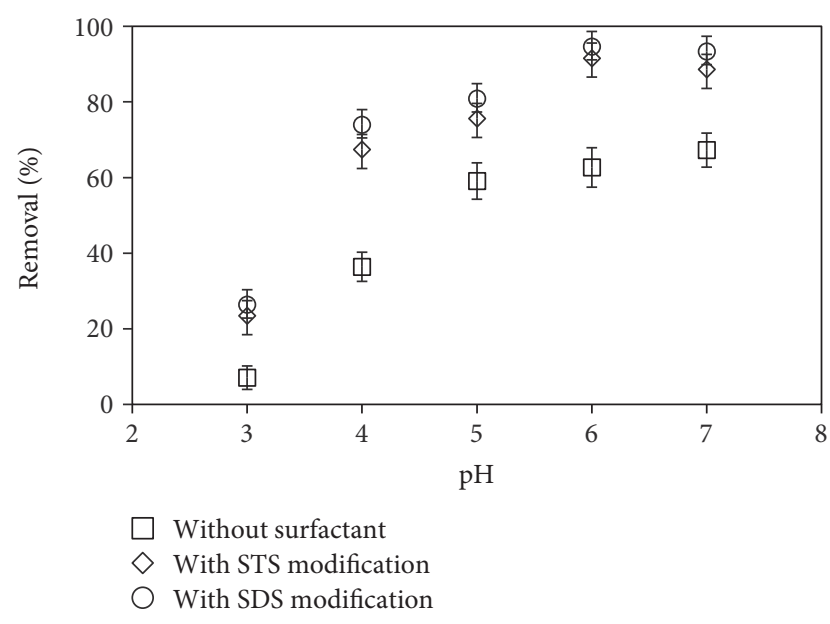

Figure 11: Influence of $\mathrm{pH}$ on removal of $\mathrm{Cd}^{2+}$ using different $\mathrm{Al}_{2} \mathrm{O}_{3}$ adsorbents (without surfactant, with STS modification, and with SDS modification) at $1 \mathrm{mM} \mathrm{NaCl}$. Error bars show standard deviations of three replicates.

the electrostatic interaction is smaller than that with salt. Nevertheless, an increase of $\mathrm{NaCl}$ concentration induced the presence of $\mathrm{Cl}^{-}$ion. When increasing salt, the concentration of $\mathrm{Cl}^{-}$is high so that the removal is decreased. This result can be also explained by desorption of SDS at high salt concentration [33]. An increase of $\mathrm{NaCl}$ concentration decreases the attraction of $\mathrm{DS}^{-}$with $\mathrm{Cd}^{2+}$ so that error bars of replicated experiments seem to be larger at high salt concentration.

3.3.4. Surface Modification of SMA after Cadmium Adsorption. Adsorption of $\mathrm{Cd}^{2+}$ onto SMA induced the charge of functional groups of SMA. Figure 14 shows the

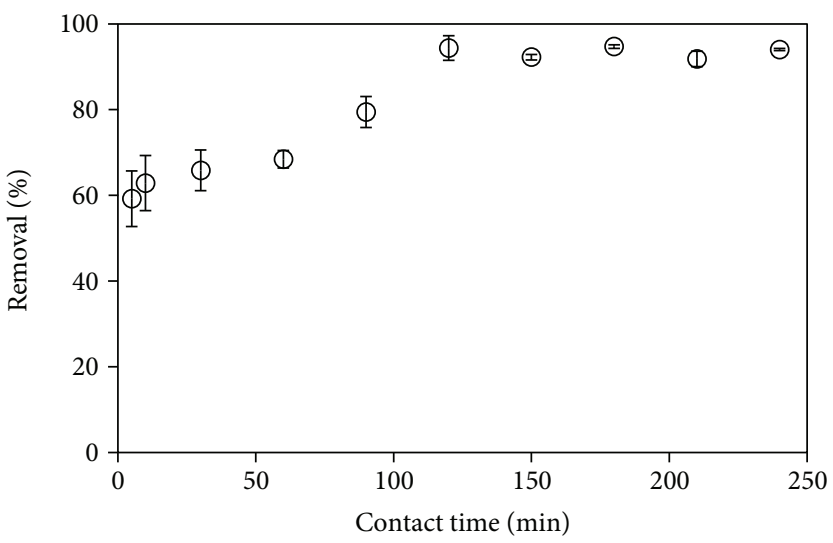

Figure 12: Influence of contact time on removal of $\mathrm{Cd}^{2+}$ using surfactant-modified $\gamma$ - $\mathrm{Al}_{2} \mathrm{O}_{3}(\mathrm{SMA})\left(C_{i}\left(\mathrm{Cd}^{2+}\right)=10 \mathrm{ppm}, \mathrm{pH} 6\right.$, $1 \mathrm{mM} \mathrm{NaCl})$. Error bars show standard deviations of three replicates.

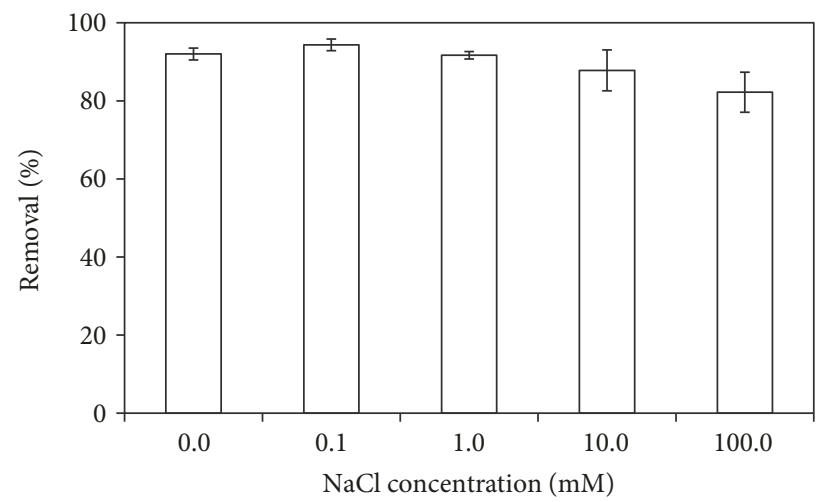

FIGURE 13: Influence of $\mathrm{NaCl}$ concentration on removal of $\mathrm{Cd}^{2+}$ using surfactant-modified $\gamma-\mathrm{Al}_{2} \mathrm{O}_{3}(\mathrm{SMA})\left(C_{i}\left(\mathrm{Cd}^{2+}\right)=10 \mathrm{ppm}, \mathrm{pH} 6\right.$, contact time $120 \mathrm{~min})$. Error bars show standard deviations of three replicates. 


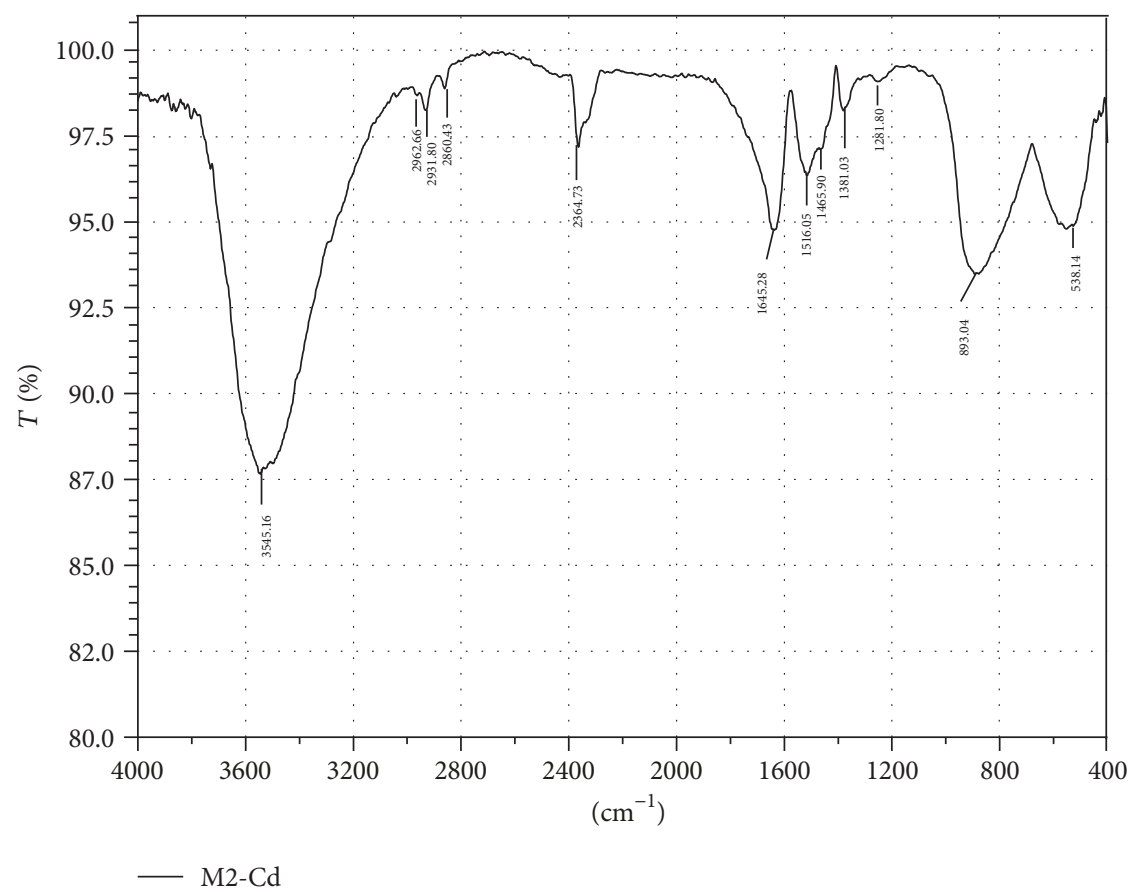

FIGURE 14: The FTIR spectra in the wavenumber range of $400-4000 \mathrm{~cm}^{-1}$ for SDS-modified $\gamma-\mathrm{Al}_{2} \mathrm{O}_{3}$ after adsorption of cadmium.

TABLE 2: Adsorption capacity and removal efficiency of $\mathrm{Cd}^{2+}$ using surfactant-modified alumina (SMA) and other absorbents.

\begin{tabular}{lccc}
\hline Adsorbent & $\begin{array}{c}\text { Adsorption } \\
\text { capacity (mg/g) }\end{array}$ & $\begin{array}{c}\text { Removal } \\
\text { efficiency (\%) }\end{array}$ & References \\
\hline $\begin{array}{l}\text { Kaolinite clay } \\
\begin{array}{l}\text { Multi-carboxyl- } \\
\text { functionalized }\end{array}\end{array}$ & 15.60 & 87.50 & {$[38]$} \\
$\begin{array}{l}\text { silica gel } \\
\text { Activated sludge }\end{array}$ & 40.48 & 89.44 & {$[39]$} \\
$\begin{array}{l}\text { Waste sludge } \\
\begin{array}{l}\text { Zeolite-based } \\
\text { geopolymer }\end{array}\end{array}$ & 18.0 & 74.5 & {$[40]$} \\
$\begin{array}{l}\text { Activated alumina } \\
\text { SMA }\end{array}$ & 35.06 & 90.0 & {$[41]$} \\
\hline
\end{tabular}

FTIR of SMA after $\mathrm{Cd}^{2+}$ adsorption. The FTIR spectra of SDS-modified $\gamma-\mathrm{Al}_{2} \mathrm{O}_{3}$ after adsorption of $\mathrm{Cd}^{2+}$ (Figure 14) indicates that the specific peaks assigned for the vibration of $\mathrm{CH}_{2}$ - in the wavenumber range of $2500 \mathrm{~cm}^{-1}-3500 \mathrm{~cm}^{-1}$ still occurred but the intensity is much smaller compared with that of SMA [37]. It implies that after adsorption of cationic $\mathrm{Cd}^{2+}$, the small number of SDS admicelles SDS remained $\gamma-\mathrm{Al}_{2} \mathrm{O}_{3}$. In other words, the adsorption of $\mathrm{Cd}^{2+}$ induced the less negatively SMA surface.

3.3.5. Comparison of the Effectiveness of SMA and Other Adsorbents. Many researchers investigated the removal of $\mathrm{Cd}^{2+}$ using different kinds of adsorbents. Nevertheless, adsorptive removal of $\mathrm{Cd}^{2+}$ using surfactant-modified alumina (SMA) has not been studied. Furthermore, the SMA which is used in the present study, achieved the highest removal efficiency compared to adsorbents (Table 2). Also, the adsorption capacity of $\mathrm{Cd}^{2+}$ on SMA is quite high when comparing with other adsorbents. This demonstrates that SMA is a novel adsorbent for the removal of $\mathrm{Cd}^{2+}$ from aqueous solutions.

\section{Conclusions}

We have studied the adsorption of alkyl sulfate surfactants, sodium dodecyl sulfate (SDS) and sodium tetradecyl sulfate (STS), onto large $\gamma-\mathrm{Al}_{2} \mathrm{O}_{3}$ beads and application for removal of heavy metal ion $\left(\mathrm{Cd}^{2+}\right)$ using surfactant-modified $\gamma-\mathrm{Al}_{2} \mathrm{O}_{3}$ (SMA). The effective adsorption conditions of SDS and STS adsorption onto $\gamma-\mathrm{Al}_{2} \mathrm{O}_{3}$ were found as contact time $180 \mathrm{~min}, \mathrm{pH} 4$, and $1 \mathrm{mM} \mathrm{NaCl}$. Adsorption isotherms of both SDS and STS onto $\gamma-\mathrm{Al}_{2} \mathrm{O}_{3}$ were fitted well by the two-step adsorption model. The adsorption of alkyl sulfate surfactants onto $\gamma-\mathrm{Al}_{2} \mathrm{O}_{3}$ was induced by electrostatic and hydrophobic interactions. However, the hydrophobic interaction is much stronger for STS adsorption than for SDS adsorption. For SDS adsorption, the electrostatic attraction is more important than hydrophobic interaction. The adsorption mechanisms were confirmed by analyzing adsorption isotherm, the change in surface charge, and surface modification by FTIR. Adsorptive removal of $\mathrm{Cd}^{2+}$ from aqueous solution using SMA was investigated. The optimum conditions for $\mathrm{Cd}^{2+}$ removal using SMA were found to be $\mathrm{pH}$ 6, contact time $120 \mathrm{~min}$, and ionic strength $0.1 \mathrm{mM} \mathrm{NaCl}$. The removal of $\mathrm{Cd}^{2+}$ increased from $62.7 \%$ (without surfactant) to about $94.6 \%$ after modification with SDS. We demonstrate that SMA is a novel adsorbent compared with other adsorbents for removal of $\mathrm{Cd}^{2+}$ from aqueous solution. 


\section{Data Availability}

(1) The data is all carried out mainly at our laboratories at the Faculty of Chemistry, VNU University of Science, Vietnam National University, Hanoi, 19 Le Thanh Tong, Hoan Kiem, Hanoi 10000, Vietnam, partly at the Center of Environmental Engineering and Chemical Safety, Vietnam Institute of Industrial Chemistry, 2 Pham Ngu Lao, Hoan Kiem, Hanoi 10000, Vietnam, and Faculty of Physics and Chemical Engineering, Le Quy Don Technical University, 236 Hoang Quoc Viet, Hanoi, Vietnam. (2) The data in the article can be accessed at the Faculty of Chemistry, VNU University of Science, Vietnam National University, Hanoi, 19 Le Thanh Tong, Hoan Kiem, Hanoi 10,000, Vietnam; Center of Environmental Engineering and Chemical Safety, Vietnam Institute of Industrial Chemistry, 2 Pham Ngu Lao, Hoan Kiem, Hanoi 10,000, Vietnam; and Faculty of Physics and Chemical Engineering, Le Quy Don Technical University, 236 Hoang Quoc Viet, Hanoi, Vietnam.

\section{Conflicts of Interest}

The authors declare that they have no competing interests.

\section{Supplementary Materials}

S1: Fourier-transform infrared spectroscopy (FTIR) of unmodified alumina shows that the peaks appearing at $3664.45 \mathrm{~cm}^{-1}$ is assigned for $-\mathrm{OH}$ stretching vibration. The absorption band at $1645.28 \mathrm{~cm}^{-1}$ is due to the water molecule in the sample [1]. The broaden peak between $893.04 \mathrm{~cm}^{-1}$ and $522.71 \mathrm{~cm}^{-1}$ confirms the bending vibration of $\mathrm{Al}-\mathrm{O}$ in $\gamma-\mathrm{Al}_{2} \mathrm{O}_{3}$. S2: Fourier-transform infrared spectroscopy (FTIR) of SDS-modified $\gamma$-Al2O 3 after adsorption of cadmium indicates that the specific peaks assigned for the vibration of $\mathrm{CH} 2-$ in the wavenumber range of $2500 \mathrm{~cm}^{-1}-3500 \mathrm{~cm}^{-1}$ still occurred but the intensity is much smaller compared with that of SMA [2]. It implies that after adsorption of cationic $\mathrm{Cd} 2^{+}$, the small number of SDS admicelles SDS remained $\gamma-\mathrm{Al}_{2} \mathrm{O}_{3}$. In other words, the adsorption of $\mathrm{Cd}^{+}$induced the less negatively SMA surface. (Supplementary Materials)

\section{References}

[1] Z. Adeel and R. G. Luthy, "Sorption and transport kinetics of a nonionic surfactant through an aquifer sediment," Environmental Science \& Technology, vol. 29, no. 4, pp. 1032-1042, 1995.

[2] S. Paria, "Surfactant-enhanced remediation of organic contaminated soil and water," Advances in Colloid and Interface Science, vol. 138, no. 1, pp. 24-58, 2008.

[3] S. Paria and K. C. Khilar, "A review on experimental studies of surfactant adsorption at the hydrophilic solid-water interface," Advances in Colloid and Interface Science, vol. 110, no. 3, pp. 75-95, 2004.

[4] J. R. Milton and T. K. Joy, "Chapter 2: adsorption of surface active agent at interface: the electrical double layer," in Surfactants and Interfacial Phenomena, pp. 39-120, John Wiley \& Sons, Inc., USA, 2012.
[5] R. Zhang and P. Somasundaran, "Advances in adsorption of surfactants and their mixtures at solid/solution interfaces," Advances in Colloid and Interface Science, vol. 123-126, pp. 213-229, 2006.

[6] R. Atkin, V. S. J. Craig, E. J. Wanless, and S. Biggs, "Mechanism of cationic surfactant adsorption at the solid-aqueous interface," Advances in Colloid and Interface Science, vol. 103, no. 3, pp. 219-304, 2003.

[7] K. Esumi and Y. Yamanaka, "Interaction between sodium dodecyl poly(oxyethylene) sulfate and alumina surface in aqueous solution," Journal of Colloid and Interface Science, vol. 172, no. 1, pp. 116-120, 1995.

[8] T. P. Goloub and L. K. Koopal, "Adsorption of cationic surfactants on silica. Comparison of experiment and theory," Langmuir, vol. 13, no. 4, pp. 673-681, 1997.

[9] E. M. Lee and L. K. Koopal, "Adsorption of cationic and anionic surfactants on metal oxide surfaces: surface charge adjustment and competition effects," Journal of Colloid and Interface Science, vol. 177, no. 2, pp. 478-489, 1996.

[10] M. Kobayashi, H. Nanaumi, and Y. Muto, "Initial deposition rate of latex particles in the packed bed of zirconia beads," Colloids and Surfaces A: Physicochemical and Engineering Aspects, vol. 347, no. 1-3, pp. 2-7, 2009.

[11] T. D. Pham, M. Kobayashi, and Y. Adachi, "Adsorption of anionic surfactant sodium dodecyl sulfate onto alpha alumina with small surface area," Colloid \& Polymer Science, vol. 293, no. 1, pp. 217-227, 2015.

[12] T. D. Pham, T. T. Do, V. L. Ha et al., "Adsorptive removal of ammonium ion from aqueous solution using surfactantmodified alumina," Environmental Chemistry, vol. 14, no. 5, pp. 327-337, 2017.

[13] A. Adak, M. Bandyopadhyay, and A. Pal, "Removal of crystal violet dye from wastewater by surfactant-modified alumina," Separation and Purification Technology, vol. 44, no. 2, pp. 139144, 2005.

[14] A. Adak, M. Bandyopadhyay, and A. Pal, "Fixed bed column study for the removal of crystal violet (C. I. Basic Violet 3) dye from aquatic environment by surfactantmodified alumina," Dyes and Pigments, vol. 69, no. 3, pp. 245251, 2006.

[15] A. Adak, A. Pal, and M. Bandyopadhyay, "Removal of phenol from water environment by surfactant-modified alumina through adsolubilization," Colloids and Surfaces A: Physicochemical and Engineering Aspects, vol. 277, no. 1-3, pp. 6368, 2006.

[16] A. K. Das, S. Saha, A. Pal, and S. K. Maji, "Surfactant-modified alumina: an efficient adsorbent for malachite green removal from water environment," Journal of Environmental Science and Health, Part A, vol. 44, no. 9, pp. 896-905, 2009.

[17] M. U. Khobragade and A. Pal, "Fixed-bed column study on removal of $\mathrm{Mn}(\mathrm{II}), \mathrm{Ni}(\mathrm{II})$ and $\mathrm{Cu}(\mathrm{II})$ from aqueous solution by surfactant bilayer supported alumina," Separation Science and Technology, vol. 51, no. 8, pp. 1287-1298, 2016.

[18] M. U. Khobragade and A. Pal, "Adsorptive removal of Mn(II) from water and wastewater by surfactant-modified alumina," Desalination and Water Treatment, vol. 57, no. 6, pp. 27752786, 2016.

[19] A. M. Gaudin and D. W. Fuerstenau, "Streaming potential studies. quartz flotation with anionic collectors," Transactions AIME, vol. 202, pp. 958-962, 1955. 
[20] B.-Y. Zhu and T. Gu, "Surfactant adsorption at solid-liquid interfaces," Advances in Colloid and Interface Science, vol. 37, no. 1-2, pp. 1-32, 1991.

[21] T. D. Pham, T. T. Bui, V. T. Nguyen et al., "Adsorption of polyelectrolyte onto nanosilica synthesized from rice husk: characteristics, mechanisms, and application for antibiotic removal," Polymer, vol. 10, no. 2, p. 220, 2018.

[22] T. D. Pham, M. Kobayashi, and Y. Adachi, "Adsorption of polyanion onto large alpha alumina beads with variably charged surface," Advances in Physical Chemistry, vol. 2014, Article ID 460942, 9 pages, 2014.

[23] T. D. Pham, M. Kobayashi, and Y. Adachi, "Adsorption characteristics of anionic azo dye onto large $\alpha$-alumina beads," Colloid \& Polymer Science, vol. 293, no. 7, pp. 1877-1886, 2015.

[24] T. D. Pham, H. H. Nguyen, N. V. Nguyen et al., "Adsorptive removal of copper by using surfactant modified laterite soil," Journal of Chemistry, vol. 2017, Article ID 1986071, 10 pages, 2017.

[25] D. W. Fuerstenau, "Streaming potential studies on quartz in solutions of aminium acetates in relation to the formation of hemi- micelles at the quartz-solution interface," The Journal of Physical Chemistry, vol. 60, no. 7, pp. 981-985, 1956.

[26] D. W. Fuerstenau and H. J. Modi, "Streaming potentials of corundum in aqueous organic electrolyte solutions," Journal of the Electrochemical Society, vol. 106, no. 4, pp. 336-341, 1959.

[27] T. D. Pham, M. Kobayashi, and Y. Adachi, "Interfacial characterization of $\alpha$-alumina with small surface area by streaming potential and chromatography," Colloids and Surfaces A: Physicochemical and Engineering Aspects, vol. 436, pp. 148-157, 2013.

[28] M. Kosmulski, "The $\mathrm{pH}$ dependent surface charging and points of zero charge. VI. Update," Journal of Colloid and Interface Science, vol. 426, pp. 209-212, 2014.

[29] A. Adak, M. Bandyopadhyay, and A. Pal, "Removal of anionic surfactant from wastewater by alumina: a case study," Colloids and Surfaces A: Physicochemical and Engineering Aspects, vol. 254, no. 1-3, pp. 165-171, 2005.

[30] S. Partyka, W. Rudzinski, B. Brun, and J. H. Clint, "Calorimetric studies of adsorption of anionic surfactants onto alumina," Langmuir, vol. 5, no. 2, pp. 297-304, 1989.

[31] M. Ishiguro and L. K. Koopal, "Surfactant adsorption to soil components and soils," Advances in Colloid and Interface Science, vol. 231, pp. 59-102, 2016.

[32] L. K. Koopal, E. M. Lee, and M. R. Böhmer, "Adsorption of cationic and anionic surfactants on charged metal oxide surfaces," Journal of Colloid and Interface Science, vol. 170, no. 1, pp. 85-97, 1995.

[33] A. M. Blokhus and K. Djurhuus, "Adsorption of poly(styrene sulfonate) of different molecular weights on $\alpha$-alumina: effect of added sodium dodecyl sulfate," Journal of Colloid and Interface Science, vol. 296, no. 1, pp. 64-70, 2006.

[34] P. Somasundaran and J. T. Kunjappu, "In-situ investigation of adsorbed surfactants and polymers on solids in solution," Colloids and Surfaces, vol. 37, pp. 245-268, 1989.

[35] M. R. Bohmer and L. K. Koopal, "Adsorption of ionic surfactants on variable-charge surfaces. 1. Charge effects and structure of the adsorbed layer," Langmuir, vol. 8, no. 11, pp. 2649-2659, 1992.
[36] D. Santhiya, S. Subramanian, K. A. Natarajan, and S. G. Malghan, "Surface chemical studies on alumina suspensions using ammonium poly(methacrylate)," Colloids and Surfaces A: Physicochemical and Engineering Aspects, vol. 164, no. 2-3, pp. 143-154, 2000.

[37] R. P. Sperline, Y. Song, and H. Freiser, "Temperature dependent structure of adsorbed sodium dodecyl sulfate at the $\mathrm{Al}_{2} \mathrm{O}_{3}$ /water interface," Langmuir, vol. 13, no. 14, pp. 3727$3732,1997$.

[38] K. O. Adebowale, I. E. Unuabonah, and B. I. Olu-Owolabi, "The effect of some operating variables on the adsorption of lead and cadmium ions on kaolinite clay," Journal of Hazardous Materials, vol. 134, no. 1-3, pp. 130-139, 2006.

[39] M. Li, M.-y. Li, C.-g. Feng, and Q.-x. Zeng, "Preparation and characterization of multi-carboxyl-functionalized silica gel for removal of $\mathrm{Cu}$ (II), Cd (II), Ni (II) and $\mathrm{Zn}$ (II) from aqueous solution," Applied Surface Science, vol. 314, pp. 1063-1069, 2014.

[40] D. W. Kim, D. K. Cha, J. Wang, and C. P. Huang, "Heavy metal removal by activated sludge: influence of Nocardia amarae," Chemosphere, vol. 46, no. 1, pp. 137-142, 2002.

[41] S. M. Lee and A. P. Davis, "Removal of $\mathrm{Cu}(\mathrm{II})$ and Cd(II) from aqueous solution by seafood processing waste sludge," Water Research, vol. 35, no. 2, pp. 534-540, 2001.

[42] H. Javadian, F. Ghorbani, H.-A. Tayebi, and S. H. Asl, "Study of the adsorption of Cd (II) from aqueous solution using zeolite-based geopolymer, synthesized from coal fly ash; kinetic, isotherm and thermodynamic studies," Arabian Journal of Chemistry, vol. 8, no. 6, pp. 837-849, 2015.

[43] T. K. Naiya, A. K. Bhattacharya, and S. K. Das, "Adsorption of $\mathrm{Cd}(\mathrm{II})$ and $\mathrm{Pb}$ (II) from aqueous solutions on activated alumina," Journal of Colloid and Interface Science, vol. 333, no. 1, pp. 14-26, 2009. 


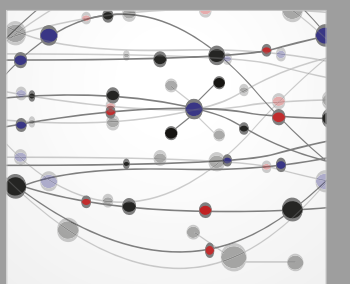

The Scientific World Journal
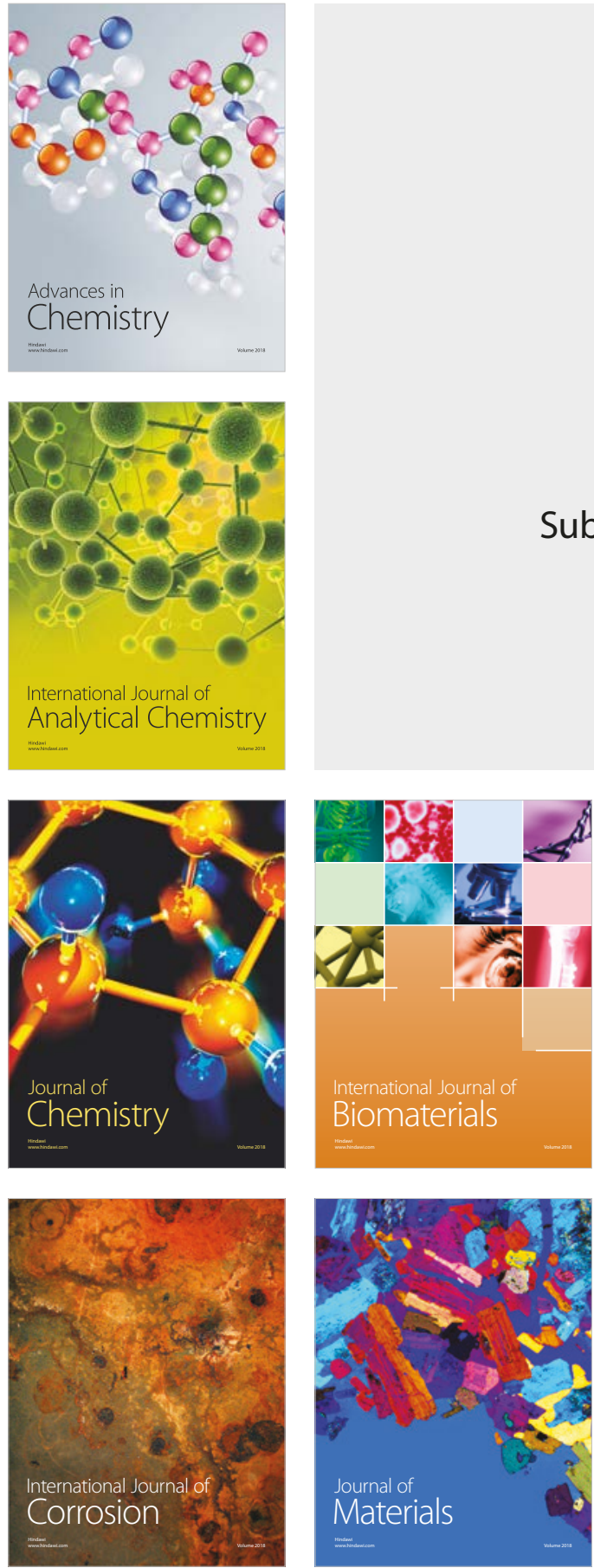

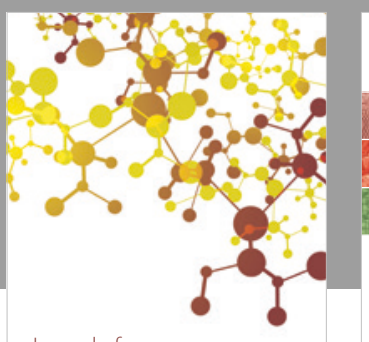

Journal of

Applied Chemistry
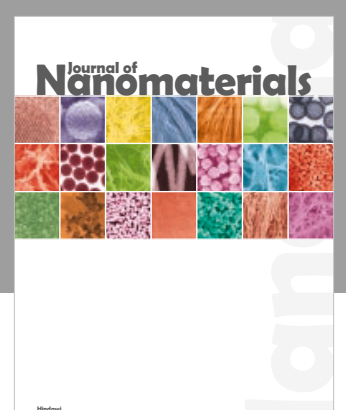

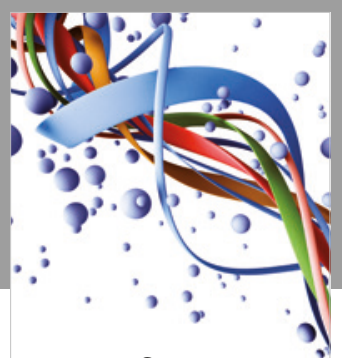

Scientifica

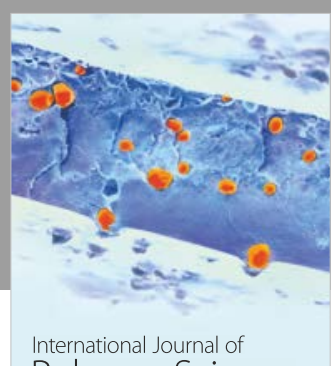

Polymer Science

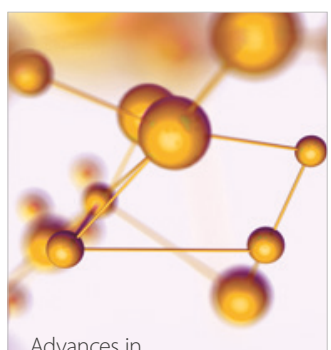

Physical Chemistry
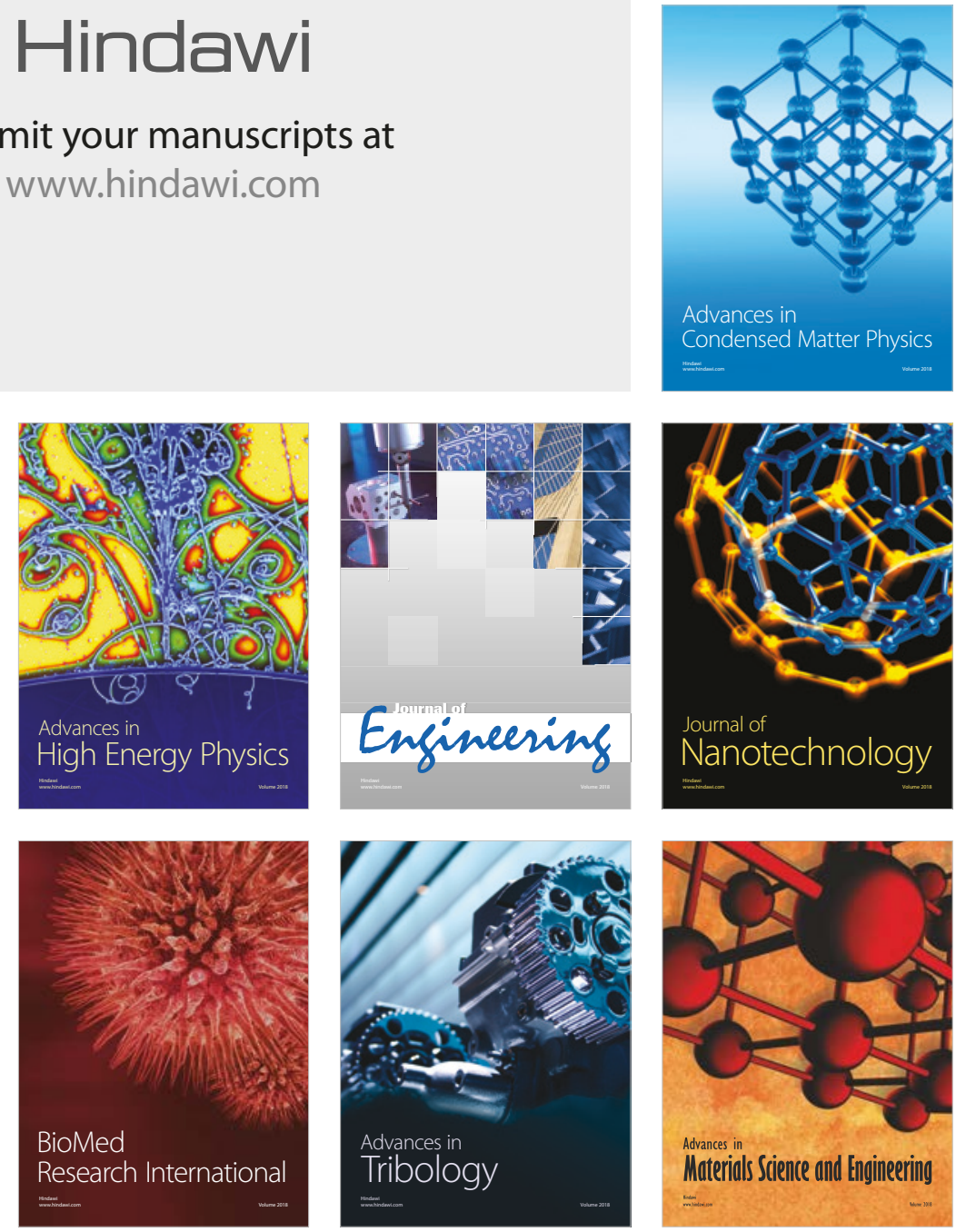